\title{
Erratum to: Beyond Crime Statistics: The Construction and Application of a Criminogenity Monitor in Amsterdam
}

\author{
Ronald van Steden • Hans Boutellier • \\ Ruben D. Scholte • Merijn Heijnen
}

Published online: 16 December 2012

(C) Springer Science+Business Media Dordrecht 2012

\section{Erratum to: Eur J Crim Policy Res (2012) DOI 10.1007/s10610-012-9179-x}

The original version of this article unfortunately contained a mistake. The presentation of Table 3 was incorrect because the grey fields were missing. The corrected Table 3 is given below.

The online version of the original article can be found at http://dx.doi.org/10.1007/s10610-012-9179-x.

R. van Steden $(\bowtie) \cdot H$. Boutellier $\cdot$ R. D. Scholte $\cdot$ M. Heijnen

Faculty of Social Sciences, Department of Governance Studies, VU University, De Boelelaan 1081, 1081 HV Amsterdam, the Netherlands

e-mail: r.van.steden@vu.nl

H. Boutellier

Verwey-Jonker Institute, Utrecht and VU University, Amsterdam, the Netherlands

R. D. Scholte

Dutch Ministry of the Interior, The Hague, the Netherlands

M. Heijnen

Municipal Department of Research and Statistics, Amsterdam, the Netherlands 


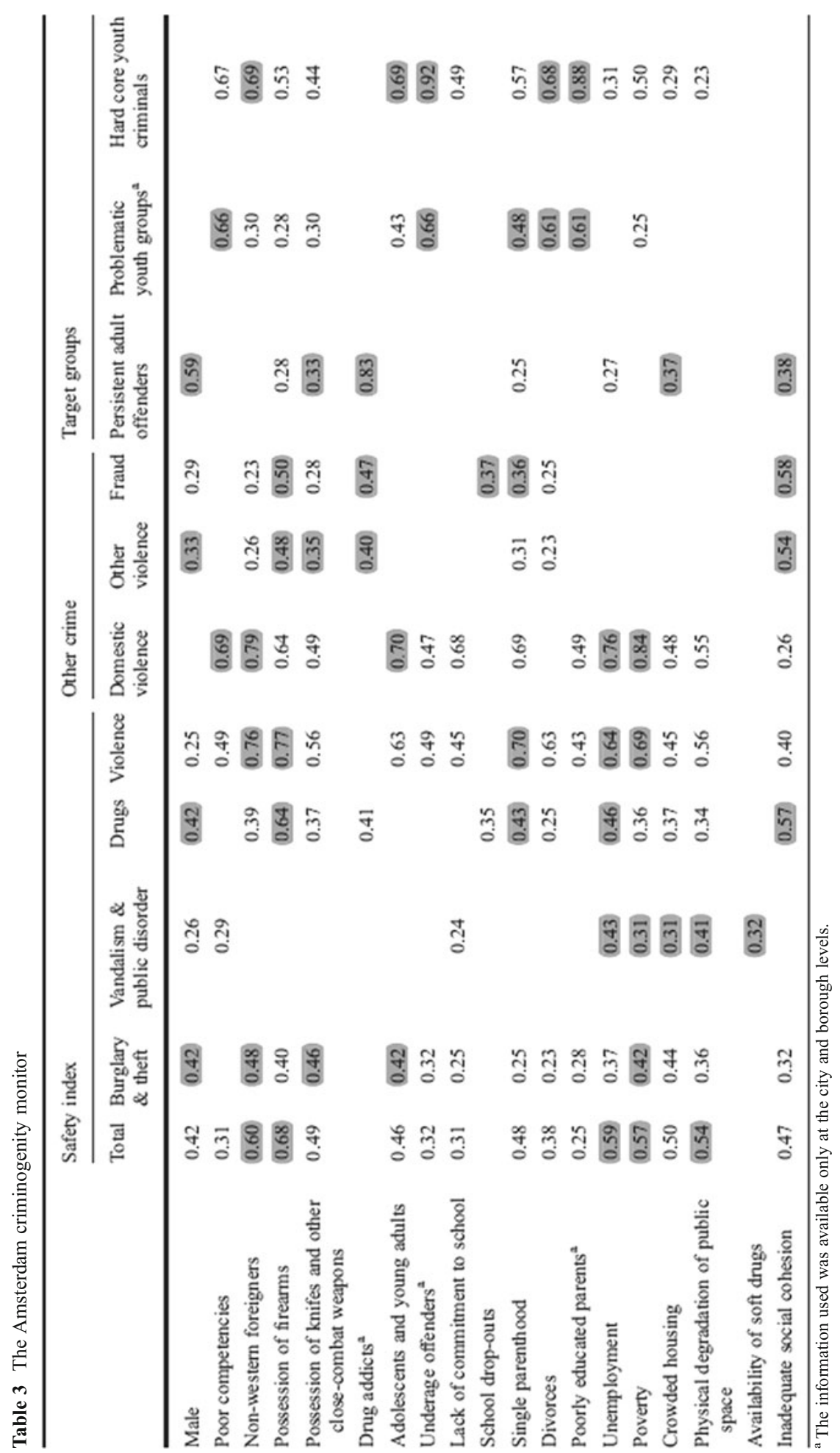

